\title{
Laboratory experiments on the influence of storm movement on overland flow
}

\author{
J.L.M.P. de Lima ${ }^{a, *}$, V.P. Singh ${ }^{b}$ \\ ${ }^{\text {a }}$ Faculty of Science and Technology (FCTUC), Department of Civil Engineering, Institute of Marine Research (IMAR)— \\ Coimbra Inter disciplinary Centre, University of Coimbra, Campus 2, 3030-290 Coimbra, Portugal \\ ${ }^{\mathrm{b}}$ Department of Civil and Environmental Engineering, Louisiana State University (LSU), Baton Rouge, LA 70803-6405, USA
}

\begin{abstract}
This study presents the results of laboratory experiments, conducted on an impermeable smooth plane surface with a movable sprinkling-type rainfall simulator, simulating a moving storm. In order to assess the effect of storm movement while eliminating variations in other factors that also influence the runoff response, the only parameters that were varied were storm velocity and direction. The results indicate considerable differences in runoff volumes and peaks and in overland flow hydrograph shapes, for storms moving upstream and downstream at differing velocities.
\end{abstract}

(C) 2003 Elsevier Science Ltd. All rights reserved.

Keywords: Overland flow; Storm movement; Rainfall simulator; Laboratory experiments

\section{Introduction}

Rainfall is frequently generated by moving storms. Overland flow under moving storms is a highly nonlinear process, essentially different from that under stationary rain-storms with respect to the temporal and spatial distributions of the input (e.g. Singh, 1998). However, although the problem of how storm movement affects flows (shape of the hydrograph and peak discharges) has been recognised for a long time (e.g. Maksimov, 1964; Yen and Chow, 1968; Wilson et al., 1979; Jensen, 1984; Singh, 1998, 2002; de Lima and Singh, 1999), most methods used in hydrologic studies assume that storms arrive instantaneously over a drainage area and then remain stationary. Therefore, these hydrologic studies do not take into account the effect on the runoff response of the storm movement across the drainage basin. Ignoring storm movement can result in (considerable) over- or under-estimation of runoff peaks (e.g. Jensen, 1984; Singh, 1998; de Lima and Singh, 2002). Knowledge of the hydrologic response to the movement of storms would also be useful in predicting the shape of overland flow hydrographs. The

\footnotetext{
${ }^{*}$ Corresponding author.

E-mail addresses: plima@dec.uc.pt (J.L.M.P. de Lima), cesing@1su.edu (V.P. Singh).
}

hydrologic response is dependent on the direction, velocity, length and pattern of the moving rainstorm.

Recent studies have also shown that the storm direction and velocity strongly affect the water erosion process. The soil loss caused by downstream moving rainstorms is greater than that caused by identical upstream moving storms (e.g. de Lima et al., 2002a,b; de Lima et al., in press). Furthermore, the raindrop splash transport process is affected by wind-driven rains (e.g. de Lima et al., 1992; van Dijk et al., 1996; Erpul et al., 2002).

The benefits of using the rainfall simulation approach in the study of overland flow are well documented, with versatility being the foremost advantage (e.g. Meyer, 1965; Bryan and Poesen, 1989; Cerdà et al., 1997). Rainfall simulation provides control of the spatial and temporal characteristics of precipitation, in both laboratory and field studies (e.g. de Lima et al., 2002c). In windy conditions the non-uniformity of simulated rainfall (e.g. rainfall intensity pattern and its temporal and spatial variability, mean drop size and drop incidence angles) can significantly influence the hydraulics of underlying overland flow (e.g. de Lima, 1989; de Lima and Torfs, 1994).

This study investigates the effect on runoff of rainstorm movement under controlled laboratory conditions. The experiments were conducted on an impermeable plane surface using a continuous full-cone nozzle 
spray rainfall simulator. Nozzle sprays produce a wide range of randomly distributed drops, rendering the simulated rainfall comparable to natural rainfall. The storm moved up or down the plane at a range of speeds, simulating a single dry-wet-dry cycle.

\section{Description of the laboratory set-up}

The laboratory equipment consisted of a tilting impermeable plane surface, a rainfall simulator and a runoff recording system for determining the overland flow hydrographs. Fig. 1 gives a diagram of the laboratory set-up.

\subsection{The flume}

The impermeable plane surface (smooth painted metal sheet) had a uniform rectangular cross-section $1.25 \mathrm{~m}$ wide and $5 \mathrm{~m}$ long, and was fixed at $5 \%$ slope. No buffer zone was used around the flume in order to compensate for water ejected outside the flume, through splash.

\subsection{The rainfall simulator}

A portable rainfall simulator was designed to move backwards and forwards, simulating moving storms (see Fig. 1). The basic components of the simulator were: a set of downward-oriented, continuous-spray, full-cone nozzles, most commonly used in rainfall simulations; a lightweight structure with wheels and two electric motors, supporting the nozzles; and the connections to the pumping system and the constant head tank (tap water was used in the rain simulations). The pumping system gives a stable pressure to avoid variations in rain intensity during the simulated rainfall events. Pressure gauges monitored the pressure at the pump and nozzle.

Although the rainfall simulator permits the use of several rows of spray nozzles, the experiments described in this study used just one nozzle, at a fixed pressure and height.

\subsection{The runoff recording system}

The runoff generated by each rainfall event was collected in a container placed at the bottom end of the flume, for the determination of the overland flow hydrographs. The runoff recording system used a high sensitivity pressure transducer connected to a data logger which recorded, in time, the water level in the container.

\section{Methodology}

The objective of this article was to study the influence of storm movement on overland flow. In order to isolate the storm movement factor, other factors that also influence the runoff response were kept constant (e.g. rainfall intensity pattern, surface characteristics).

\subsection{Storm velocity, duration and direction}

In the laboratory experiments the storm moved up and down the slope (upstream and downstream). Experiments were carried out at various storm movement velocities (higher and lower than the average overland flow velocity on the plane surface). For the slope used in the experiments, the measured mean overland flow velocity was $U=0.23 \mathrm{~m} / \mathrm{s}$, estimated by a visually traced

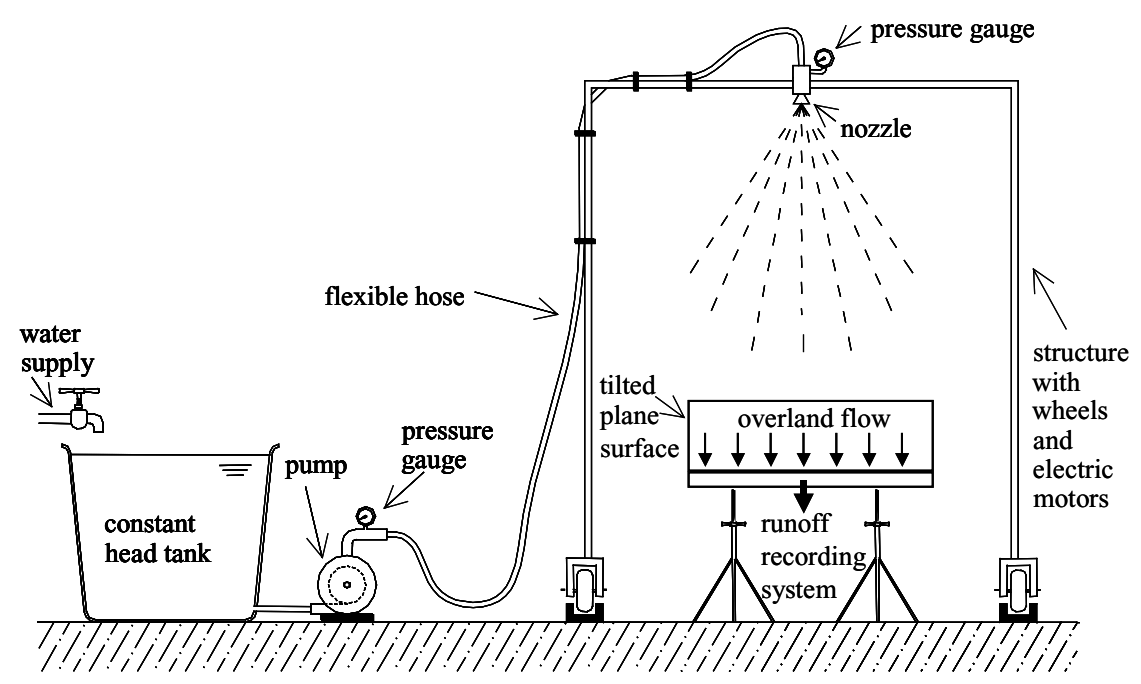

Fig. 1. Schematic representation of the laboratory set-up for simulating moving storms including the rainfall simulator and its movable support structure, the connections to the water supply, and the flume (tilted plane surface). 
dye (Abrahams et al., 1986; Li et al., 1996) and salt tracing (Luk and Merz, 1992). Storm duration was dependent on storm movement velocity: slow-moving storms stay over the surface longer. The total amount of rain also depended on storm velocity since the rainfall intensity pattern did not vary.

\subsection{Rainfall intensity pattern}

A recent study has emphasized the importance of spatial rainfall intensity patterns of moving storms on the shape of the runoff hydrographs, times to peak and peak discharges (e.g. de Lima and Singh, 2002). However, in this study, only one simulated rainfall pattern was used, as shown in Fig. 2. The storm movement was therefore accomplished by displacing this fixed rainfall pattern across the flume. The total length of the moving storm, in the longitudinal direction of the flume, was 2.7 $\mathrm{m}$. Therefore, the length of the moving rainstorm was shorter than the overland flow surface which was $5 \mathrm{~m}$ long (i.e., the storm did not, at any time, cover the entire surface of the flume).

Rainfall intensity and uniformity were determined by the nozzle size and type, the water pressure and the height of nozzle above the plot surface. The nozzle was

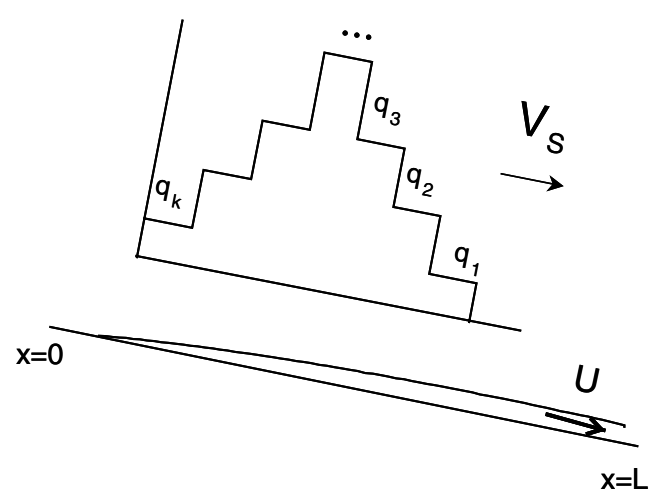

Fig. 2. Sketch of a storm moving downstream on an impermeable plane surface, where: $V_{\mathrm{S}}$ is the velocity of the rainstorm; $x$ is the distance from top of plane along the flow direction; $L$ is the total length measured along the slope; $U$ is the mean overland flow velocity; and $q_{k}$ is the rainfall intensity. tested using operating pressures of $200 \mathrm{kPa}$. The distance from the nozzle to the flume was set at $2.0 \mathrm{~m}$. The estimated average drop-size (equivalent drop diameter) was approximately $1.5 \mathrm{~mm}$ (de Lima, 1997). The measurements were taken using the stain method (e.g., Hall, 1970).

The intensity and distribution of the simulated rainfall, under the area targeted by the nozzle, was characterized by placing 36 gauges (diameter: $0.10 \mathrm{~m}$ ) under the nozzle, keeping it static. There were 9 rows spaced $0.30 \mathrm{~m}$ apart in the longitudinal direction, each with 4 gauges spaced at intervals of $1.25 / 4 \cong 0.31 \mathrm{~m}$, symmetrically distributed with respect to the nozzle. Several rainfall-distribution tests ( 2 min duration) demonstrated the reproducibility of a given rainfall intensity and the respective coefficient of uniformity.

The geometrically invariant pattern of a storm generated by the moving nozzle can be simplified, as shown in Fig. 2, assuming only one-dimension (along the longitudinal direction of the flume). This assumption will be useful in future comparisons with one-dimensional numerical modelling results.

Table 1 and Fig. 3 summarise the spatial distribution of rainfall intensity on the plane surface, which corresponds to a mean rainfall intensity of $89 \times 10^{-6} \mathrm{~m} / \mathrm{s}$ and a discharge of $3 \times 10^{-4} \mathrm{~m}^{3} / \mathrm{s}$, at steady state. Uniformity of rainfall application was determined using the Christiansen (1942) equation:

$C_{\text {unif }}=100\left(1-\frac{\sum_{i=1}^{n}\left|x_{i}\right|}{\bar{x} n}\right)$

where $C_{\text {unif }}$ is the uniformity coefficient $(\%), x_{i}$ is the deviation from the mean value $\bar{x}$, and $n$ is the number of gauges employed, for each rainfall intensity $q_{k}$, as shown in Figs. 2 and 3.

\subsection{Surface characteristics}

The surface characteristics were exactly the same (air dry flume) for all the simulated events. In addition, the position of the flume did not change with respect to the storm movement. The nozzle moved along the vertical plane that contains the longitudinal centre axis of the flume. The testing was limited to a single bed slope (5\%).

Table 1

Rainfall intensities on the plane surface, $q_{k}$, and respective uniformity coefficients, $C_{\text {unif }}$ (Christiansen, 1942), measured with the nozzle kept static at a height of $2.0 \mathrm{~m}$, for an operating pressure of $200 \mathrm{kPa}$ (see also Figs. 2 and 3)

\begin{tabular}{llll}
\hline Position $k$ & Number of gauges employed $n$ & Rainfall intensity $q_{k}(\mathrm{~mm} / \mathrm{s})$ & Uniformity coefficient $C_{\text {unif }}(\%)$ \\
\hline 1 and 9 & 8 & 0.0155 & 82 \\
2 and 8 & 8 & 0.0651 & 86 \\
3 and 7 & 8 & 0.1034 & 96 \\
4 and 6 & 8 & 0.1342 & 91 \\
5 & 4 & 0.1646 & 86 \\
\hline
\end{tabular}




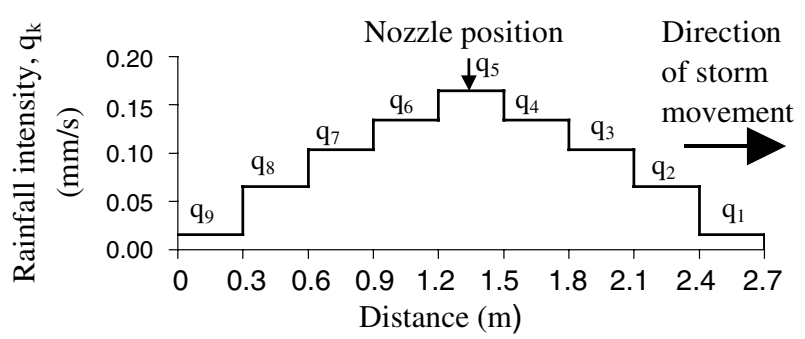

Fig. 3. Measured distribution of rainfall intensities under the nozzle in a static position, for operating pressure of $200 \mathrm{kPa}$ at $2.0 \mathrm{~m}$ of height (see also Table 1). Nozzle is positioned at the middle point $(1.35 \mathrm{~m})$.

\section{Results}

Fig. 4 clearly illustrates the effect of the storm direction (upstream or downstream) and velocity on the
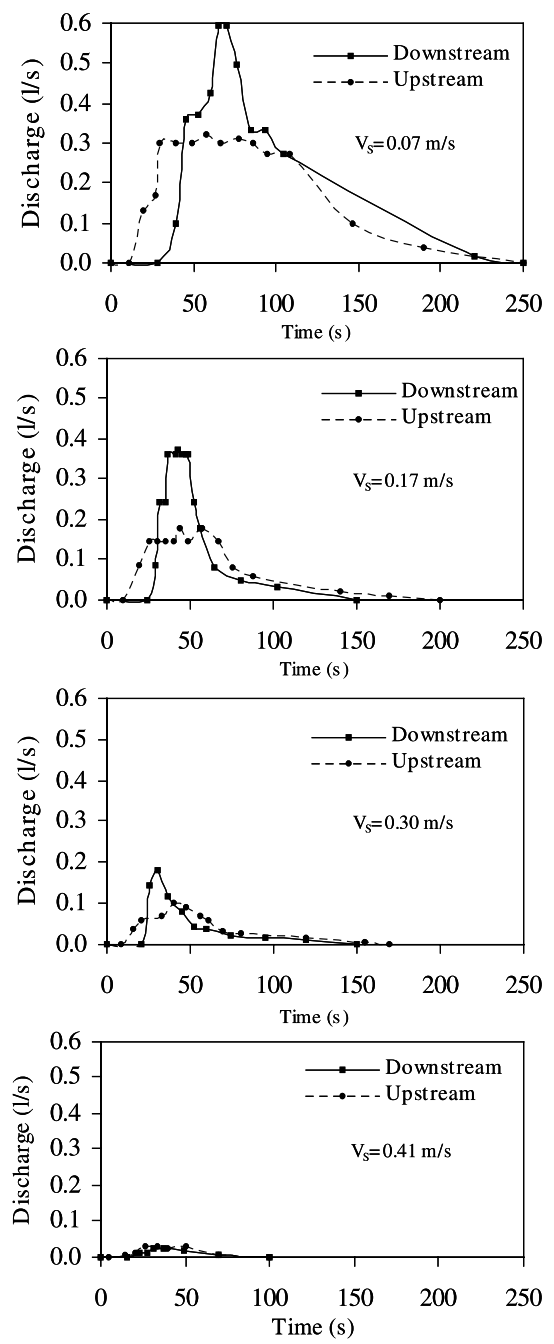

Fig. 4. Effect of direction of storm movement (upstream and downstream) on measured hydrographs for 4 storm velocities. The duration of the storms (e.g. total time from the instant the rainfall enters until it leaves the surface) are: $110 \mathrm{~s}$ (top figure), 45, 25 and $19 \mathrm{~s}$ (bottom figure). hydrologic response. The overland flow hydrographs are characterized by marked differences in runoff volumes and peaks, times of rise and shapes.

In the experiments, as soon as the simulated rainstorm reached the dry impervious surface, the water started to accumulate owing to surface tension, without overland flow occurring. When the amount of water increased to an amount such that surface tension could no longer overcome the gravitational force, the water started flowing.

When the storm is moving in the downstream direction, which is also the direction of the flow, the beginning of runoff at the lower end of the plane is dependent on both the storm velocity and the surface flow velocity. If the former is greater than the latter, the storm reaches the lower end first and the runoff initially observed is the contribution of the precipitation in the vicinity of the outlet. Therefore, the arrival of the water contribution from the upper areas of the plane will be delayed.

When the storm is moving in the upstream direction, the initiation of runoff at the lower end of the plane (time of rise) is less dependent on the overland flow and storm velocity, and is expected shortly after the storm enters the plane. As Figs. 4 and 5 show, a rainstorm moving upstream produces a hydrograph that has a much earlier rise than that for downstream-moving storms.

Since the simulated rainfall was invariant in time, irrespective of the velocity of the storm, slow-moving storms are expected to produce a large amount of runoff volume, higher peak discharge and longer base times (Fig. 4). On the other hand, fast moving storms are expected to produce smaller amounts of runoff and, due to surface tension forces, the differences between the hydrographs for downstream and upstream moving storms become negligible (Fig. 4, bottom).

A rainstorm moving downstream produces higher peak discharges than the same storm moving upstream, at the same velocity (Fig. 4). The difference between the peak discharges for downstream- and upstream-moving storms is dependent on storm velocity, as shown in Fig. 6.

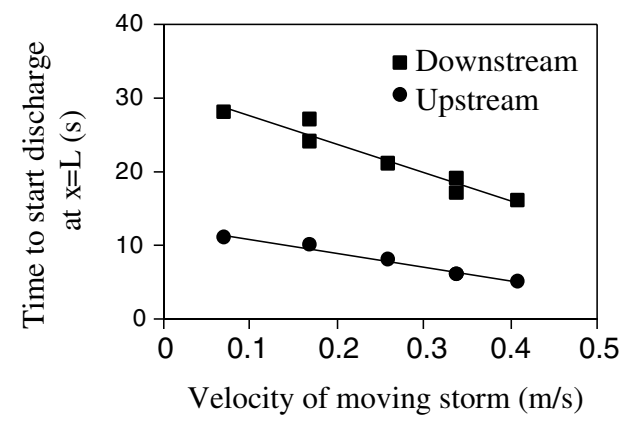

Fig. 5. Time of rise (e.g. time to start discharge at $x=L$ ) as a function of storm velocity for rainstorms moving in the upstream and downstream directions. 


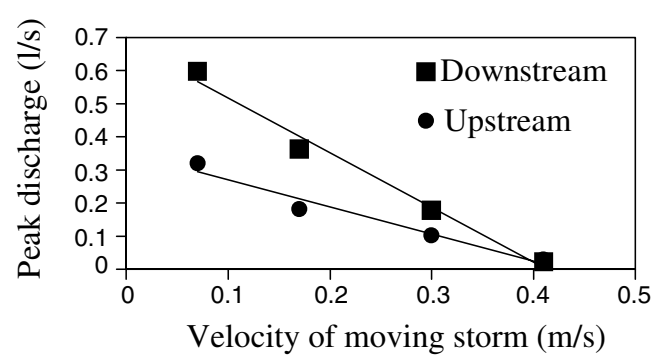

Fig. 6. Peak discharge as a function of storm velocity for rainstorms moving in the upstream and downstream directions.

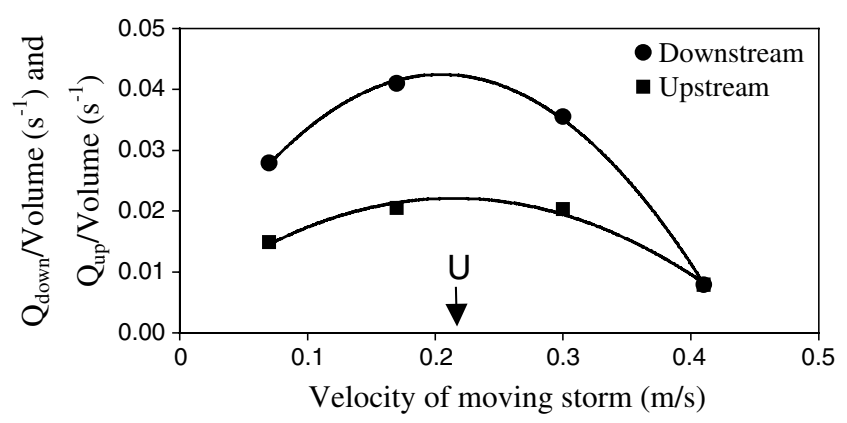

Fig. 7. Ratio of peak discharge and total runoff volume as a function of the velocity of storms moving upstream and downstream, where: $Q_{\text {down }}$ is the peak discharge for a storm moving downstream; $Q_{\text {up }}$ is the peak discharge for a storm moving upstream; Volume is the total runoff volume; and $U$ is the mean overland flow velocity.

The effect of storm velocity and direction is further seen in the relation presented in Fig. 7, where the ratio between peak discharge and total runoff volume is plotted against storm velocity, for downstream- and upstream-moving storms. For storms moving in the downstream direction the relative peak discharge is greatest for a storm velocity equal to the mean overland flow velocity, as shown in Fig. 7. This is also true for storms moving upstream. Similar results are reported by Singh (1998), using analytical solutions based on the kinematic wave equations.

\section{Conclusion}

The overland flow hydrographs presented in this study were obtained in the laboratory with equipment consisting of a rainfall simulator (single full-cone nozzle spray), an impermeable overland flow plane, and a runoff recording system. The results indicate considerable differences in runoff volumes and peaks and hydrograph shapes, for storms moving up and down the plane (i.e. upstream- and downstream-moving storms) at different velocities.

Thus, it can be concluded that there are two distinct hydrologic responses for storms moving upstream and downstream. Storms moving upstream, when compared with storms moving downstream, are characterised by hydrographs with: (1) earlier rise; (2) lower peak discharge; and (3) longer base time. Furthermore, for storms moving in both the downstream and upstream directions, the relative peak discharge is greatest for a storm velocity equal to the mean overland flow velocity.

Future laboratory and field experiments will test relationships for a wider range of conditions that will include the use of other rainfall intensity patterns of moving storms and infiltrating surfaces. Future work should also include the comparison of the experimental results with numerical results (e.g. non-linear kinematic wave theory).

\section{Acknowledgements}

This study was funded by the Foundation for Science and Technology (Research Project FCT-POCTI/ 35661/MGS/2000) of the Portuguese Ministry of Science and Technology, Lisbon, Portugal, within the Programme POCTI. The laboratory experiments described in this study were conducted in the Department of Civil Engineering of the Faculty of Science and Technology, University of Coimbra (Portugal). Some of the experimental runs reported in this study were conducted with the help of Sónia Correia, at that time a student on the Civil Engineering Course of the Department of Civil Engineering of the University of Coimbra, in Portugal.

\section{References}

Abrahams, A.D., Parsons, A.J., Luk, S.H., 1986. Field measurement of the velocity of overland flow using dye tracing. Earth Surface Processes and Landforms 11, 653-657.

Bryan, R.B., Poesen, J., 1989. Laboratory experiments on the influence of slope length on runoff, percolation and rill development. Earth Surface Processes and Landforms 14, 211-231.

Cerdà, A., Ibáñez, S., Calvo, A., 1997. Design and operation of a small and portable rainfall simulator for rugged terrain. Soil Technology $11,163-170$.

Christiansen, J.E., 1942. Irrigation by sprinkling. Bull. No. 670, California Agric. Experiment Station, University of California, Berkeley, CA.

de Lima, J.L.M.P., 1989. The influence of the angle of incidence of the rainfall on the overland flow process. In: Kavvas, M.L. (Ed.), New Directions for Surface Water Modeling. IAHS Publ. 181, p. 73-82.

de Lima, J.L.M.P., 1997. Modelação de simuladores de chuva com nebulizadores de cone preenchido. In: Acta do $3^{\circ}$ Simpósio de Hidráulica e Recursos Hídricos dos Países de Língua Oficial Portuguesa ( $3^{\circ}$ SILUSBA), vol. II. APRH/AMCT/ABRH, 15-17 de Abril de 1997, Maputo, Moçambique, p. 10 (in Portuguese).

de Lima, J.L.M.P., Torfs, P.J.J.F., 1994. Effects of wind on simulated rainfall and overland flow under single full-cone nozzle sprays. In: Tsakiris, G., Santos, M.A. (Eds.), Proceedings of the Second European Conference on Advances in Water Resources Technology and Management Lisbon. Balkema, Portugal, pp. 443-450.

de Lima, J.L.M.P., Singh, V.P., 1999. The influence of storm movement on overland flow-Laboratory experiments under simulated rainfall. In: Singh, V.P., Won Seo, I., Sonu, J.H. (Eds.), 
Hydrological Modeling. Water Resources Publications, USA, pp. 101-111.

de Lima, J.L.M.P., Singh, V.P., 2002. The influence of the pattern of moving rainstorms on overland flow. Advances on Water Resources $25(7), 817-828$.

de Lima, J.L.M.P., van Dijk, P.M., Spaan, W.P., 1992. Splashsaltation transport under wind-driven rain. Journal of Soil Technology 5, 151-166.

de Lima, J.L.M.P., Singh, V.P., Barreira, I.M., de Lima, M.I.P., 2002a. Laboratory experiments on the influence of storm direction on soil loss from sloping areas. In: Singh, V.P., Al-Rashid, M., Sherif, M.M. (Eds.), Surface Water Hydrology. A.A. Balkema Publishers, Swets \& Zeitlinger, Lisse, The Netherlands, pp. 405416.

de Lima, J.L.M.P., de Lima, M.I.P., Singh, V.P., 2002b. The importance of the velocity, direction and length of moving storms on water erosion. In: Faz, A., Ortiz, A.R., Mermut, A.R. (Eds.), Sustainable Use and Management of Soils in Arid and Semiarid Regions, vol. II. International Symposium SUMASS2002, Murcia, Cartagena, Spain, 22-26 September 2002, Quaderna Editorial, Interlibro, pp. 236-237.

de Lima, J.L.M.P., Torfs, P.J.J.F., Singh, V.P., 2002c. A mathematical model for evaluating the effect of wind on downward-spraying rainfall simulators. CATENA 46, 221-241.

de Lima, J.L.M.P., Singh, V.P., de Lima, M.I.P., in press. The influence of storm movement on water erosion: Storm velocity and direction effects. CATENA, Elsevier.

Erpul, G., Norton, L.D., Gabriels, D., 2002. Raindrop-induced and wind-driven soil particle transport. Catena 47, 227-243.
Hall, M.J., 1970. Use of the stain method in determining the drop-size distributions of coarse liquid sprays. Transactions of the ASAE 41, 33-37.

Jensen, M., 1984. Runoff pattern and peak flows from moving block rains based on linear time-area curve. Nordic Hydrology 15, 155168.

Li, G., Abrahams, A.D., Atkinson, J.F., 1996. Correction factors in the determination of mean velocity of overland flow. Earth Surface Processes and Landforms 21, 509-515.

Luk, S.H., Merz, W., 1992. Use of the salt tracing technique to determine the velocity of overland flow. Soil Technology 5, 71-78.

Maksimov, V.A., 1964. Computing runoff produced by a heavy rainstorm with a moving center. Soviet Hydrology 5, 510-513.

Meyer, L.D., 1965. Simulation of rainfall for soil erosion research. Transactions of the ASAE 8, 63-65.

Singh, V.P., 1998. Effect of the direction of storm movement on planar flow. Hydrological Processes 12, 147-170.

Singh, V.P., 2002. Effect of the duration and direction of storm movement on infiltrating planar flow with full areal coverage. Hydrological Processes 16, 1479-1511.

van Dijk, P.M., de Lima, J.L.M.P., Stroosnijder, L., 1996. The influence of rainfall on transport of beach sand by wind. Earth Surface Processes and Landforms 21, 341-352.

Wilson, C.B., Valdes, J.B., Rodrigues-Iturbe, I., 1979. On the influence of the spatial distribution of rainfall on storm runoff. Water Resources Research 15 (2), 321-328.

Yen, B.C., Chow, V.T., 1968. A study of surface runoff due to moving rainstorms. Hydraulic Engineering Series No. 17, Department of Civil Engineering, University of Illinois, Urbana, USA. 